Full Length Article

\title{
Nearly-zero valence band and large conduction band offset at BAlN/GaN heterointerface for optical and power device application
}

\author{
Haiding Sun ${ }^{\mathrm{a}}$, Young Jae Park ${ }^{\mathrm{b}}$, Kuang-Hui Li ${ }^{\mathrm{a}}$, Xinwei Liu ${ }^{\mathrm{a}}$, Theeradetch Detchprohm ${ }^{\mathrm{b}}$, Xixiang Zhang, \\ Russell D. Dupuis ${ }^{\mathrm{b}}$, Xiaohang Li ${ }^{\mathrm{a},}$, \\ ${ }^{a}$ King Abdullah University of Science and Technology (KAUST), Advanced Semiconductor Laboratory, Thuwal 23955-6900, Saudi Arabia \\ ${ }^{\mathrm{b}}$ Center for Compound Semiconductors and School of Electrical and Computer Engineering, Georgia Institute of Technology, Atlanta, GA 30332, USA \\ ${ }^{c}$ Division of Physical Science and Engineering, King Abdullah University of Science and Technology, Thuwal 23955-6900, Saudi Arabia
}

\section{A R T I C L E I N F O}

\section{Keywords:}

Band alignment

BAlN

GaN

Heterointerface

LED

Laser

Power device

\begin{abstract}
A B S T R A C T
Wurtzite BAlN alloy with large bandgap is an emerging material system for UV optoelectronic and power devices. In this study, the BAlN/GaN heterojunction with a sharp interface and uniform distribution of the elements was formed by careful control of epitaxial conditions to avoid GaN desorption and parasitic reactions whose band alignment was then measured for the first time. The valence band offset (VBO) was found to be nearly-zero, i.e. $-0.2 \pm 0.2 \mathrm{eV}$, in the $\mathrm{B}_{0.14} \mathrm{Al}_{0.86} \mathrm{~N} / \mathrm{GaN}$ heterojunction by $\mathrm{X}$-ray photoelectron spectroscopy. Additionally, the conduction band offset (CBO) is estimated at $2.1 \pm 0.2 \mathrm{eV}$, which is the largest reported $\mathrm{CBO}$ among epitaxial GaN-based heterojunctions. In comparison to the type- $\mathrm{Al}_{0.75} \mathrm{Ga}_{0.25} \mathrm{~N} / \mathrm{GaN}$ heterojunction (both $\mathrm{Al}_{0.75} \mathrm{Ga}_{0.25} \mathrm{~N}$ and $\mathrm{B}_{0.14} \mathrm{Al}_{0.86} \mathrm{~N}$ alloy have the same bandgap of $5.7 \mathrm{eV}$ ), the $\mathrm{CBO}$ and $\mathrm{VBO}$ of the $\mathrm{B}_{0.14} \mathrm{Al}_{0.86} \mathrm{~N} / \mathrm{GaN}$ heterostructure are significantly larger and smaller, respectively. The nearly-zero $\mathrm{VBO}$ and the very large $\mathrm{CBO}$ of the $\mathrm{B}_{0.14} \mathrm{Al}_{0.86} \mathrm{~N} /$ GaN heterojunction could potentially lead to considerable performance enhancement for GaN optoelectronics and power electronics devices.
\end{abstract}

\section{Introduction}

GaN has an energy bandgap of $\sim 3.4 \mathrm{eV}$ with a large breakdown field of $3.3 \mathrm{MV} / \mathrm{cm}$. Due to these two inherently material properties relevant to power devices, GaN and its ternary alloys such as AlGaN have been widely studied and applied [1]. In the past decade, both lateral power electronics based on an AlGaN/GaN heterostructure [2,3] and vertical GaN devices [4,5] have been implemented. By taking advantage of the discontinuity of the polarization in the conventional AlGaN/GaN heterojunction, a relatively high density $\left(\sim 10^{13} / \mathrm{cm}^{2}\right)$ of two-dimensional electron gas (2DEG) can be easily formed at heterojunction interface, leading to a lateral high electron mobility transistor (HEMT) [2]. To further improve the transport properties of such transistors and to have superior electrical characteristics, a high density of the 2DEG with large electron mobility is necessary. However, the current configuration of the GaN transistors using the AlGaN/GaN lateral heterojunction limits its power handling (only a few $\mathrm{kW}$ maximum) due to the existence of interfacial defects and electron scattering mech- anisms in an AlGaN/GaN structure [6]. Furthermore, a space between the gate and drain in a HEMT has to be large enough to achieve relatively high breakdown voltages, thus a larger bandgap of semiconductor material might be preferred in the barrier layer [7].

Wurtzite BAlN alloy possesses a large bandgap of $\sim 6.5 \mathrm{eV}[8,9]$. An earlier study has shown that it is beneficial to introduce B in the AlGaN-based multiple quantum wells in the active region of emitters, where the UV light emission could be significantly improved by at least four times [10]. High reflectivity distributed Bragg reflectors based on high refractive index contrast $\mathrm{B}_{\mathrm{x}} \mathrm{Al}_{1-\mathrm{x}} \mathrm{N} / \mathrm{AlN}$ structures have also been reported [11]. However, due to the strong parasitic reaction in reactor, small diffusion length of the $\mathrm{B}$ atoms and the possible phase separation, the B-composition of the BAlN alloys remains low [11]. Until recently, we have successfully grown single-phase BAlN layer with high-boron composition above $10 \%$ by metalorganic chemical vapor deposition (MOCVD) [12-14], which paves the way for the exploration of BAlN-contained heterojunctions for device application. We have also reported the band alignment of the BAlN/Al-rich AlGaN heterojunction for deep UV optoelectronics [15]. For GaN-based power electronics and

\footnotetext{
* Corresponding author.

Email addresses: haiding.sun@kaust.edu.sa (H. Sun); xiaohang.li@kaust.edu.sa (X. Li)
} 


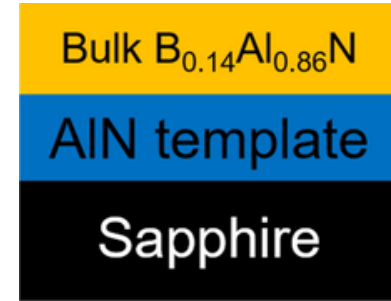

Sample A

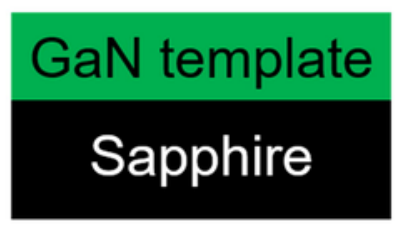

Sample B

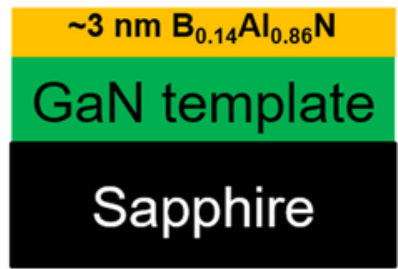

Sample C

Fig. 1. Schematics of the three investigated samples.
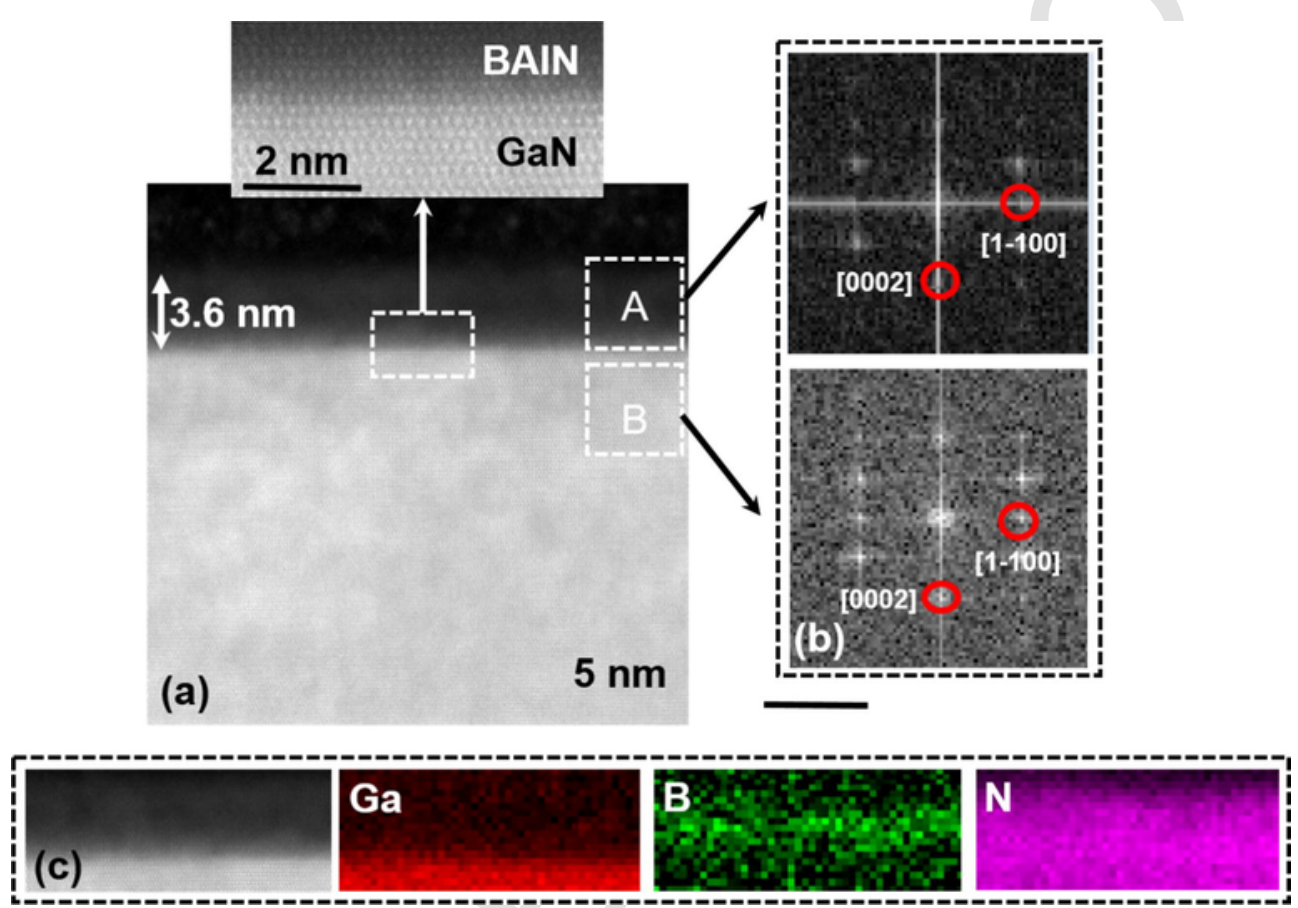

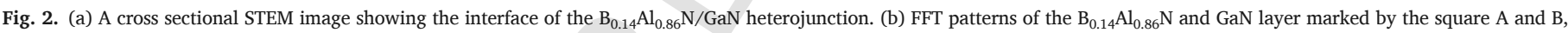
respectively. (c) EELS elemental distribution of $\mathrm{Ga}, \mathrm{B}$, and $\mathrm{N}$ at the junction.

near-UV optoelectronics, furthermore, BAlN could be employed for enhanced device performance as well. For instance, BAlN could serve as the barrier layer by replacing the AlGaN layer to form a BAlN/GaN heterojunction in a HEMT. In attempting the possibility of adopting a BAlN/GaN heterojunction in such devices, the band lineup at the BAlN/ GaN structure is an essential factor since it influences the 2DEG density and the carrier transport. However, the growth of such heterojunctions and the corresponding band alignment measurement have not been reported.

In this work, we measured the band lineup, including the valence band offset (VBO) and conduction band offset (CBO), of the MOVPE-grown $\mathrm{B}_{0.14} \mathrm{Al}_{0.86} \mathrm{~N} / \mathrm{GaN}$ heterojunctions. The growth conduction of the $\mathrm{B}_{0.14} \mathrm{Al}_{0.86} \mathrm{~N}$ layer on GaN template was optimized. The structural quality and the element distribution of such heterojunction were also investigated by transmission electron microscope. Additionally, we calculated the band structures and 2DEG density by using a $\mathrm{B}_{0.14} \mathrm{Al}_{0.86} \mathrm{~N} /$ $\mathrm{GaN}$ and $\mathrm{AlGaN} / \mathrm{GaN}$ heterojunction for a typical HEMT, respectively. The results are compared and analyzed.

\section{Material growth and methods}

Three samples were prepared by an AIXTRON close-coupled showerhead MOVPE reactor using triethylboron (TEB), trimethylaluminium (TMA), trimethylgallium (TMG), and $\mathrm{NH}_{3}$ as precursors with $\mathrm{H}_{2}$ as the carrier gas. Sample A has a thicker $\mathrm{B}_{0.14} \mathrm{Al}_{0.86} \mathrm{~N}$ layer $(40 \mathrm{~nm})$ deposited on an AlN template, Sample B is a GaN template $(3 \mu \mathrm{m})$, and Sample C is a $\mathrm{B}_{0.14} \mathrm{Al}_{0.86} \mathrm{~N} / \mathrm{GaN}$ heterojunction with an approximately $3 \mathrm{~nm}$ thick $\mathrm{B}_{0.14} \mathrm{Al}_{0.86} \mathrm{~N}$ layer. Fig. 1 shows the schematics for the three investigated samples. It is important to note that the growth of sharp $\mathrm{B}_{0.14} \mathrm{Al}_{0.86} \mathrm{~N}$ / $\mathrm{GaN}$ heterointerface is more challenging than that of the $\mathrm{B}_{0.14} \mathrm{Al}_{0.86} \mathrm{~N}$ / $\mathrm{Al}_{0.7} \mathrm{Ga}_{0.3} \mathrm{~N}$ heterointerface we grew previously [15] because of the well-known issue of GaN surface desorption amid the growth condition ramping process. Thus the delicate control of $\mathrm{NH}_{3}$ was important to suppress the GaN desorption. The flow of $\mathrm{NH}_{3}$ was kept at $1.29 \times 10^{-1} \mathrm{~mol}$ / min while the reactor temperature was ramping up to the growth temperature of unintentionally-doped (UID) GaN film $\left(1075^{\circ} \mathrm{C}\right)$. During the GaN growth, the flow of $\mathrm{NH}_{3}$ was increased to $1.70 \times 10^{-1} \mathrm{~mol} / \mathrm{min}$. Then the flow of $\mathrm{NH}_{3}$ was tuned down gradually to $3.35 \times 10^{-3} \mathrm{~mol}$ / min after the completion of the UID-GaN growth while the temperature of the reactor was ramping down to $1010^{\circ} \mathrm{C}$, preparing for the BAlN growth. Due to the strong parasitic reaction between $\mathrm{NH}_{3}$ and TEB, the $\mathrm{NH}_{3}$ supply was kept at such low supply rate $\left(3.35 \times 10^{-3} \mathrm{~mol} / \mathrm{min}\right.$, similar to the growth condition of BAlN in Ref. [15]) to avoid any precipitation and incorporation of premature reaction by-products in the BAlN layer until the growth was fully completed to ensure the formation of the $\mathrm{B}_{0.14} \mathrm{Al}_{0.86} \mathrm{~N} / \mathrm{GaN}$ heterojunction with the sharp interface. 

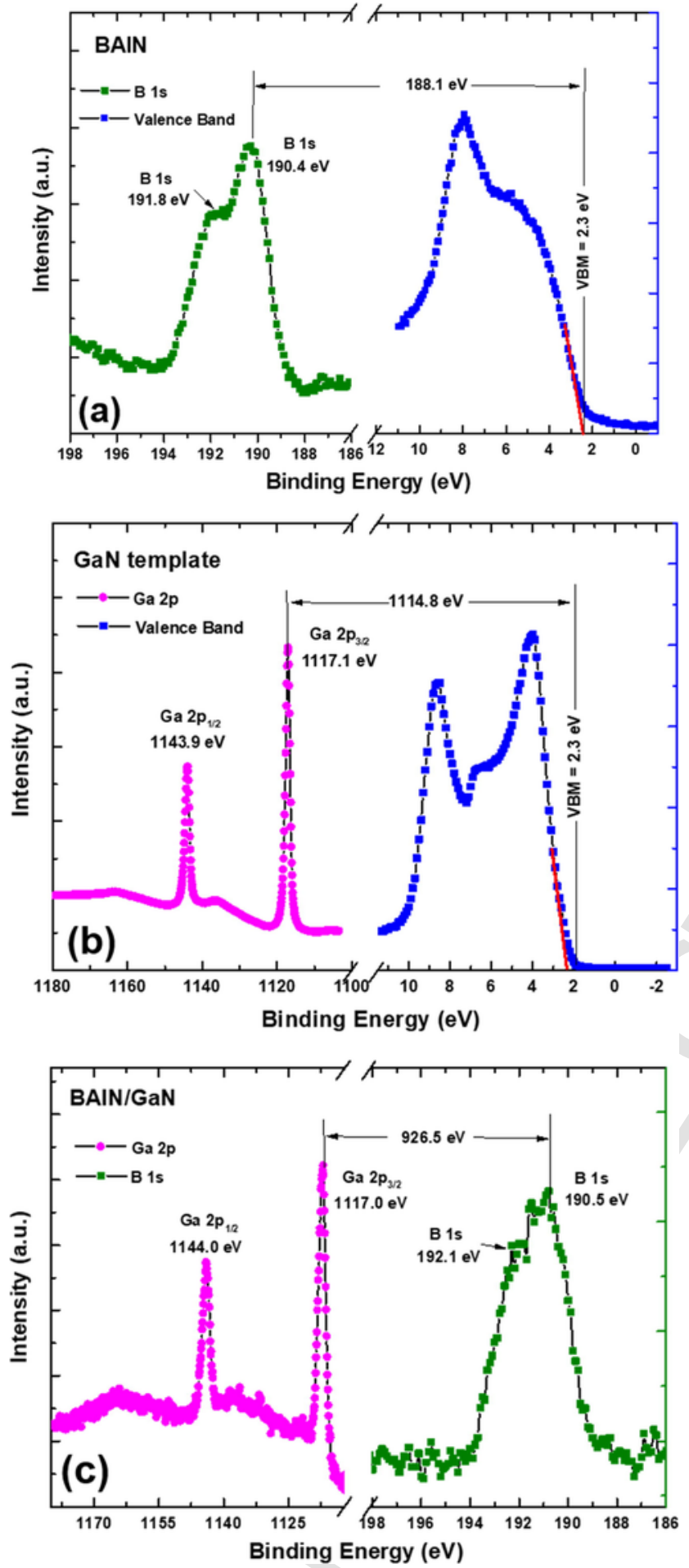

Fig. 3. (a) The XPS spectra of $\mathrm{B} 1 \mathrm{~s}$ core-level and the VBM of the $\mathrm{B}_{0.14} \mathrm{Al}_{0.86} \mathrm{~N}$ layer in Sample A; (b) The Ga $2 \mathrm{p}_{3 / 2} \mathrm{CL}$ and VBM of the GaN template in Sample B; (c) The Ga $2 \mathrm{p}_{3 / 2}$ and $\mathrm{B} 1 \mathrm{~s}$ CLs at the $\mathrm{B}_{0.14} \mathrm{Al}_{0.86} \mathrm{~N} / \mathrm{GaN}$ heterointerface (Sample C).

To verify the epitaxial relationship and interface quality, a high-resolution scanning transmission electron microscopy (STEM) was used (FEI Probe-corrected Titan). The chemical distribution for the boron, nitrogen, gallium elements in the various layers was also carried out by collecting electron energy-loss spectroscopic (EELS) spectra. FEI Helios scanning electron microscope was used to prepare the TEM sample. A high-resolution X-ray photoelectron spectroscopy (HR-XPS) was implemented to collect the energy core levels (CLs) for each element and

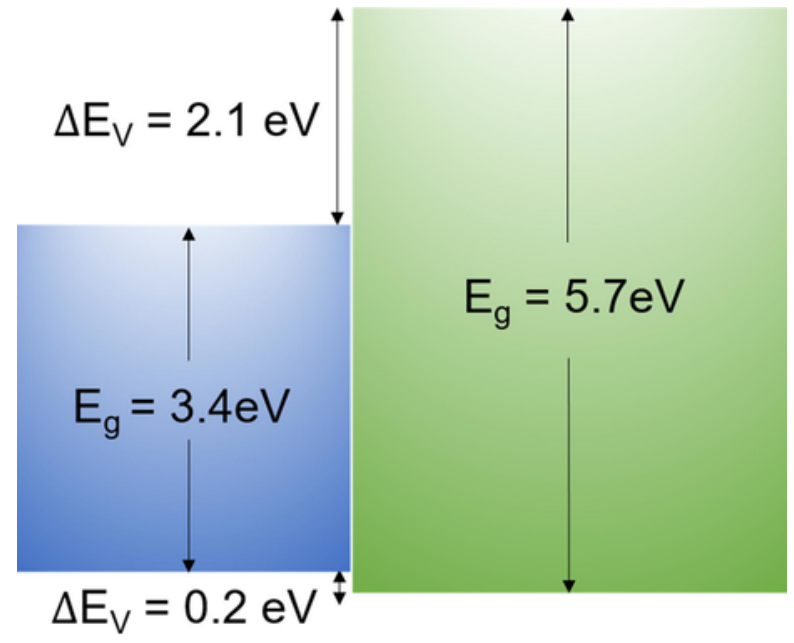

\section{GaN $\quad \mathrm{B}_{0.14} \mathrm{Al}_{0.86} \mathrm{~N}$}

Fig. 4. Schematic of the band lineup for the $\mathrm{B}_{0.14} \mathrm{Al}_{0.86} \mathrm{~N} / \mathrm{GaN}$ heterointerface. A type-I lineup is found.

photoemission spectra of the individual layer. This technique is widely adopted to investigate the VBOs of two semiconductor materials at the interface including our previous studies [15-18]. The $\mathrm{B}_{0.14} \mathrm{Al}_{0.86} \mathrm{~N}$ layer of Sample C must be thin enough to allow the CLs spectra from the bottom GaN layer to be detected. A slight surface oxidation could happen due to the air exposure in the process of wafer transferring between the MOVPE chamber to XPS chamber but we did not perform any additional wafer cleaning to avoid unnecessary possible surface contamination. The XPS study was performed in a Kratos Axis Supra DLD spectrometer which has a monochromatic $\mathrm{Al} \mathrm{K}_{\alpha} \mathrm{X}$-ray source $(h \nu=1486.6 \mathrm{eV})$. The details of the spectrometer setup can be referred elsewhere $[15,16]$. The $\mathrm{C} 1 \mathrm{~s}$ peak (binding energy is $284.8 \mathrm{eV}$ ) was used as the reference to extract the values for all CLs. The resolution limit in the equipment is smaller than $0.1 \sim 0.2 \mathrm{eV}$.

\section{Results and discussions}

The STEM result in Fig. 2(a) exhibits an abrupt interface at the heterojunction. A layer of $3.6 \mathrm{~nm} \mathrm{~B}_{0.14} \mathrm{Al}_{0.86} \mathrm{~N}$ is identified. Fig. 2(b) represents two Fast Fourier Transform (FFT) results corresponding to the $\mathrm{B}_{0.14} \mathrm{Al}_{0.86} \mathrm{~N}$ and $\mathrm{GaN}$ layer, indicating a good epitaxial alignment along (0002) direction between the two layers with a single-phase wurtzite structure. Fig. 2(c) displays the elemental distribution of B, Ga, and $\mathrm{N}$ across the interface by the EELS scan, representing an even distribution of these elements in different layers.

The core levels of the $\mathrm{B} 1 \mathrm{~s}$ and $\mathrm{Ga} 2 \mathrm{p}$ signals were adopted in the process of the evaluation of the VBO result at the $\mathrm{B}_{0.14} \mathrm{Al}_{0.86} \mathrm{~N} / \mathrm{GaN}$ heterointerface. Following the procedure firstly described by Kraut et al. [19], the $\mathrm{VBO}(\Delta \mathrm{Ev})$ at the $\mathrm{B}_{0.14} \mathrm{Al}_{0.86} \mathrm{~N} / \mathrm{GaN}$ heterointerface can be estimated by the equation as below:

$$
\begin{aligned}
\Delta \mathrm{E}_{\mathrm{v}}= & \left(\mathrm{E}_{\mathrm{B} 1 \mathrm{~s}}^{\mathrm{BAlN}}-\mathrm{E}_{\mathrm{VBM}}^{\mathrm{BAIN}}\right)-\left(\mathrm{E}_{\mathrm{Ga} 2 \mathrm{p} 3 / 2}^{\mathrm{GaN}}-\mathrm{E}_{\mathrm{VBM}}^{\mathrm{GaN}}\right) \\
& +\left(\mathrm{E}_{\mathrm{Ga} 2 \mathrm{p} 3 / 2}^{\mathrm{BAIN}}-\mathrm{E}_{\mathrm{B} 1 \mathrm{~s}}^{\mathrm{BAIN} / \mathrm{GaN}}\right)
\end{aligned}
$$

The term of $\mathrm{E}_{\mathrm{B} 1 \mathrm{~s}}^{\mathrm{BAlN}}-\mathrm{E}_{\mathrm{VBM}}^{\mathrm{BAIN}}$ is the core level of the $\mathrm{B} 1 \mathrm{~s}$ which can be extracted in accordance to the valence band maximum (VBM) in the Sample A.

Fig. 3(a) presents the $\mathrm{B} 1 \mathrm{~s}$ CL signal acquired from the $\mathrm{B}_{0.14} \mathrm{Al}_{0.86} \mathrm{~N}$ layer has two different peaks. The peak energies of $190.4 \mathrm{eV}$ and $191.8 \mathrm{eV}$ correspond to the $\mathrm{B}$ and oxidized $\mathrm{B}$ complex in the 

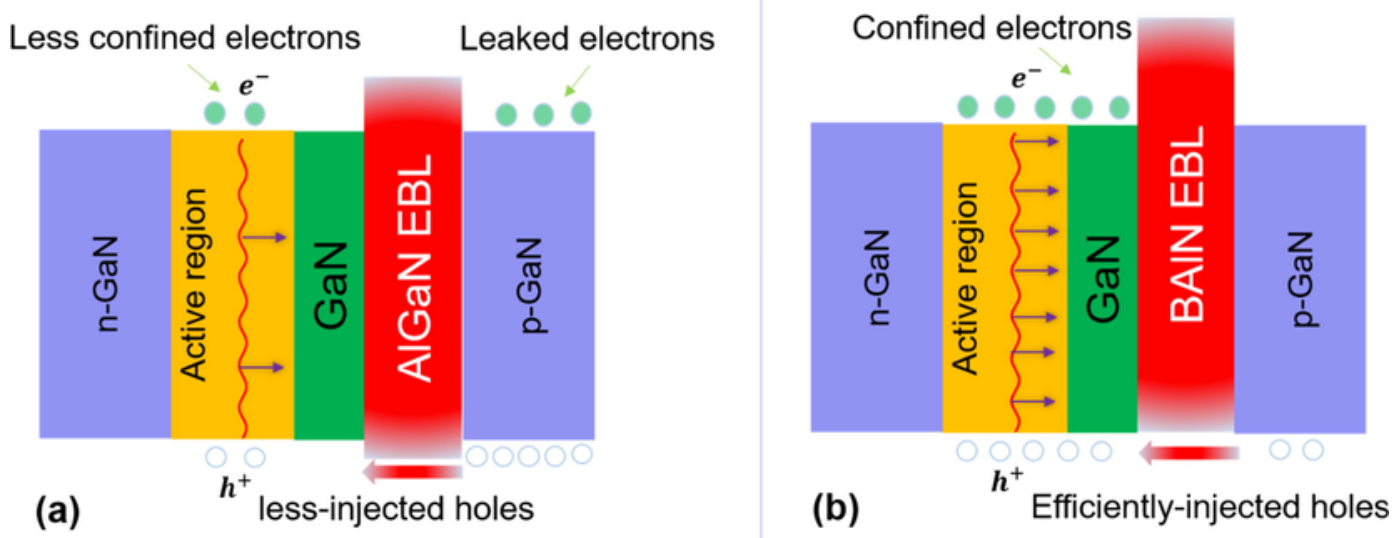

Fig. 5. Schematics of a light emitting device using (a) a conventional AlGaN layer and (b) a BAlN layer as the EBL.

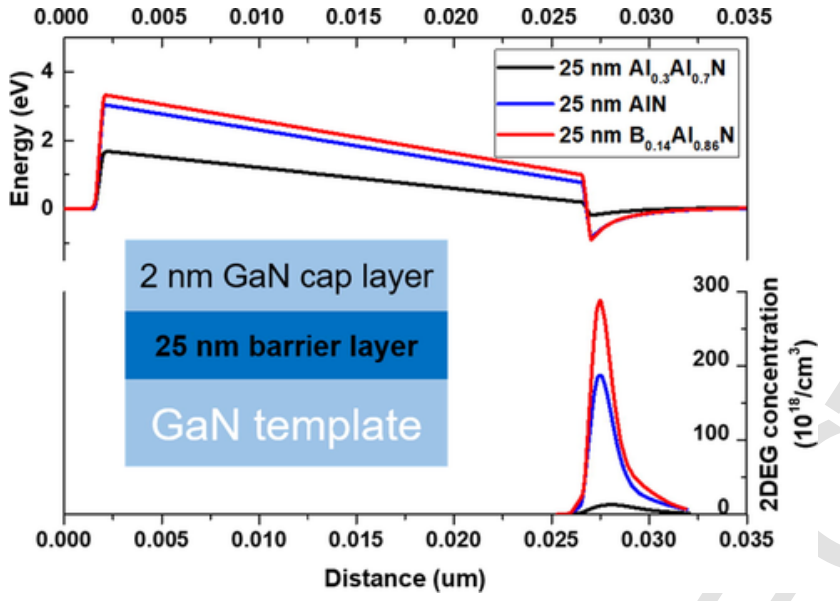

Fig.6. The 2DEG distribution and its potential profile versus the distance (z) in a GaN $(2 \mathrm{~nm}) /$ barrier layer/GaN template heterojunction with $25 \mathrm{~nm}$ barrier layer using a $\mathrm{B}_{0.14} \mathrm{Al}_{0.86} \mathrm{~N}, \mathrm{Al}_{0.3} \mathrm{Ga}_{0.7} \mathrm{~N}$ and AlN layer, respectively. The inset shows the schematic of such heterostructure.

$\mathrm{B}_{0.14} \mathrm{Al}_{0.86} \mathrm{~N}$ layer [20]. The oxidized B signal could origin from the sample transferring process to the XPS chamber which is inevitable. The VBM in the $\mathrm{B}_{0.14} \mathrm{Al}_{0.86} \mathrm{~N}$ layer was extracted to be around $2.3 \mathrm{eV}$. As a result, regarding the $\mathrm{B}_{0.14} \mathrm{Al}_{0.86} \mathrm{~N}$ layer, the difference between the CL of $\mathrm{B}$ $1 \mathrm{~s}$ and its VBM $\left[\Delta \mathrm{E}=\mathrm{E}_{\mathrm{B} 1 \mathrm{~s}}^{\mathrm{BAiN}}-\mathrm{E}_{\mathrm{VBM}}^{\mathrm{BAlN}}\right]$ is determined to be $188.1 \mathrm{eV}$. Similarly, we collected the CL spectrum of Ga $2 \mathrm{p}_{3 / 2}$ and the VBM and extract their difference $\left[\Delta \mathrm{E}=\mathrm{E}_{\mathrm{Ga} 2 \mathrm{p}}^{\mathrm{GaN}}-\mathrm{E}_{\mathrm{VBM}}^{\mathrm{GaN}}\right]$ to be $1114.8 \mathrm{eV}$ for the $\mathrm{GaN}$ layer, as displayed in Fig. 3(b). Lastly, the CL energy separation between the B $1 \mathrm{~s}$ and the Ga $2 \mathrm{p}_{3 / 2}$ signal from Sample C was measured. Fig. 3(c) presents the CL of the $\mathrm{B} 1 \mathrm{~s}$ located at $190.5 \mathrm{eV}$ along with the oxidized B peak position at $192.1 \mathrm{eV}$. The $\mathrm{Ga} 2 \mathrm{p}_{3 / 2} \mathrm{CL}$ energy is found to be $1117.3 \mathrm{eV}$. Therefore, the energy separation between the CLs of Ga $2 \mathrm{p}_{3 /}$ ${ }_{2}$ and the $\mathrm{B} 1 \mathrm{~s}$, based on the formula $\left[\Delta \mathrm{E}=\mathrm{E}_{\mathrm{Ga} 2 \mathrm{p}}^{\mathrm{BAIN} / \mathrm{GaN}}-\mathrm{E}_{\mathrm{B} 1 \mathrm{~s}}^{\mathrm{BAIN} / \mathrm{GaN}}\right]$, is calculated to be $926.5 \mathrm{eV}$.

Thereby, based on the Eq. (1), we can obtain the VBO in this heterojunction to be $\Delta E_{v}=-0.2 \hat{\mathrm{A}} \pm 0.2 \mathrm{eV}$. In consequence, after substituting the $\mathrm{VBO}$ value and the energy bandgaps of the semiconductors $\mathrm{B}_{0.14} \mathrm{Al}_{0.86} \mathrm{~N}\left(\mathrm{E}_{g}=5.7 \mathrm{eV}\right)$ [8] and $\mathrm{GaN}\left(\mathrm{E}_{g}=3.4 \mathrm{eV}\right)$ [23] based on the Eq. (2), we can now determine the $\mathrm{CBO}\left(\Delta \mathrm{E}_{c}\right)$ at the $\mathrm{B}_{0.14} \mathrm{Al}_{0.86} \mathrm{~N} / \mathrm{GaN}$ heterointerface. And the $\mathrm{CBO}\left(\Delta \mathrm{E}_{\mathrm{c}}\right)$ is estimated to be $2.1 \pm 0.2 \mathrm{eV}$.

$\Delta \mathrm{E}_{c}=\mathrm{E}_{g}^{\mathrm{BAlN}}+\Delta \mathrm{E}_{v}-\mathrm{E}_{g}^{\mathrm{GaN}}$
We compare this value with the value of $\Delta \mathrm{E}_{c}$ in conventional $\mathrm{Al}_{\mathrm{x}} \mathrm{Ga}_{1-\mathrm{x}} \mathrm{N} / \mathrm{GaN}$ heterostructure as extracted below:

The bandgap of $\mathrm{Al}_{\mathrm{x}} \mathrm{Ga}_{1-\mathrm{x}} \mathrm{N}$ is given by Ambacher et al. [21]:

$\mathrm{E} g(x)=x \hat{A} \cdot \operatorname{Eg}(\mathrm{AlN})+(1-x) \hat{A} \cdot \mathrm{Eg}(\mathrm{GaN})-x \hat{A} \cdot(1-x)$

where we replace the bandgap values of the $\mathrm{AlN}\left(\mathrm{E}_{g}=6.1 \mathrm{eV}\right)$ and the $\mathrm{GaN}\left(\mathrm{E}_{g}=3.4 \mathrm{eV}\right)$ of a $\mathrm{Al}_{\mathrm{x}} \mathrm{Ga}_{1-\mathrm{xN}} / \mathrm{GaN}$ junction, the $\mathrm{CBO}$ of the $\mathrm{Al}_{\mathrm{x}} \mathrm{Ga}_{1-\mathrm{x}} \mathrm{N} / \mathrm{GaN}$ heterojunctions is given by

$\mathrm{CBO}=\mathrm{E} g(\mathrm{x})-\mathrm{VBO}-\mathrm{E} g$

where $\mathrm{E}_{g}(\mathrm{x})$ is the bandgap of $\mathrm{Al}_{\mathrm{x}} \mathrm{Ga}_{1-\mathrm{x}} \mathrm{N}$ and $\mathrm{E}_{g}$ the energy bandgap of $\mathrm{GaN}$. Thus, the fact that the energy band-offsets of the AlGaN/GaN heterostructure can be taken as $70 \%(30 \%)$ for the conduction (valence) band [22], we can calculate the $\mathrm{CBO}$ and $\mathrm{VBO}$ of $\mathrm{Al}_{\mathrm{x}} \mathrm{Ga}_{1-\mathrm{x}} \mathrm{N} / \mathrm{GaN}$ structure. We found a significantly smaller $\mathrm{CBO}(1.4 \mathrm{eV})$ and larger VBO $(0.5 \mathrm{eV})$ in the $\mathrm{Al}_{0.75} \mathrm{Ga}_{0.25} \mathrm{~N} / \mathrm{GaN}$ heterojunction compared with these values in the $\mathrm{B}_{0.14} \mathrm{Al}_{0.86} \mathrm{~N} / \mathrm{GaN}$ heterojunction, although the $\mathrm{Al}_{0.75} \mathrm{Ga}_{0.25} \mathrm{~N}$ has an identical bandgap of the $\mathrm{B}_{0.14} \mathrm{Al}_{0.86} \mathrm{~N}$ alloy.

Then the experimental band alignments at the $\mathrm{B}_{0.14} \mathrm{Al}_{0.86} \mathrm{~N} / \mathrm{GaN}$ junction is plotted, as described in Fig. 4. It is suggested that the $\mathrm{B}_{0.14} \mathrm{Al}_{0.86} \mathrm{~N} / \mathrm{GaN}$ heterostructure has a type-I lineup behavior which indicates that it can be used for light emitting devices. Particularly, due to the larger $\mathrm{CBO}(2.1 \mathrm{eV})$ and nearly zero $\mathrm{VBO}$ in such junction compared with a conventional AlN/GaN heterostructure in which the $\mathrm{CBO}$ and $\mathrm{VBO}$ are 1.9 and $0.7 \mathrm{eV}$, respectively [23], we anticipate that the UV-transparent $\mathrm{B}_{0.14} \mathrm{Al}_{0.86} \mathrm{~N}$ alloy can act as a quantum barrier to have a better electron confinement in the active region or as an electron blocking layer (EBL) (as schematically shown in Fig. 5(b)). The $\mathrm{B}_{0.14} \mathrm{Al}_{0.86} \mathrm{~N}$ layer may facilitate hole injection in a blue and near-UV light emitting diodes by replacing the widely-used AlGaN EBL layer (as shown Fig. 5(a)), thus improving III-nitride light emitters' performance.

Furthermore, the $\mathrm{B}_{0.14} \mathrm{Al}_{0.86} \mathrm{~N}$ alloy can possibly offer the largest CBO with the GaN layer in the application of HEMTs, thus we calculate the band structure and the density of 2DEG of a $\mathrm{B}_{0.14} \mathrm{Al}_{0.86} \mathrm{~N}$ / $\mathrm{GaN}$ heterostructure and compare it with the conventional $\mathrm{Al}_{0.3} \mathrm{Ga}_{0.7} \mathrm{~N}$ / $\mathrm{GaN}$ and $\mathrm{AlN} / \mathrm{GaN}$ heterostructures [7,24]. The thickness of the barrier layer $\left(\mathrm{B}_{0.14} \mathrm{Al}_{0.86} \mathrm{~N}, \mathrm{Al}_{0.3} \mathrm{Ga}_{0.7} \mathrm{~N}\right.$, and $\left.\mathrm{AlN}\right)$ and $\mathrm{GaN}$ cap layer are chosen to be 25 and $2 \mathrm{~nm}$ [7]. The calculation was performed by using the self-consistent coupled Schrödinger and the Poisson formulas in a commercially available software APSYS provided by the Crosslight Software Inc [25]. The potential profiles (band structures) and the distribution of the 2-DEG density are displayed in the Fig. 6. Noticeably, we 
found that the peak of the 2DEG concentration is drastically enhanced from $80 \times 10^{18} \mathrm{~cm}^{-3}$ to $400 \times 10^{18} \mathrm{~cm}^{-3}$, and then to $680 \times 10^{18} \mathrm{~cm}^{-3}$ by using the $\mathrm{Al}_{0.3} \mathrm{Ga}_{0.7} \mathrm{~N}$, AlN, and $\mathrm{B}_{0.14} \mathrm{Al}_{0.86} \mathrm{~N}$ as the barrier, respectively. Even though the increase of the 2DEG is quite attractive if we replace the conventional $\mathrm{Al}_{0.3} \mathrm{Ga}_{0.7} \mathrm{~N}$ barrier by the $\mathrm{B}_{0.14} \mathrm{Al}_{0.86} \mathrm{~N}$, we must take into account the critical thickness of the barrier layer. Its impact on the interface quality needs to be ascertained in a real device because it has a significant influence on the mobility and 2DEG density in such heterostructure. In a real HEMT, an AlN intermediate layer will be inserted in conventional $\mathrm{Al}_{0.3} \mathrm{Ga}_{0.7} \mathrm{~N} / \mathrm{GaN}$-based device, leading to a significant enhancement of the mobility due to the removal of alloy scattering [26,27]. Previous study has proved that the mobility of carriers can be achieved up to $2100 \mathrm{~cm}^{2} / \mathrm{Vs}$ because of the reduced electron spillover into the $\mathrm{Al}_{0.3} \mathrm{Ga}_{0.7} \mathrm{~N}$ layer and smaller alloy scattering [28]. Therefore, we can replace the AlN interlayer by the BAlN interlayer in an $\mathrm{Al}_{0.3} \mathrm{Ga}_{0.7} \mathrm{~N} / \mathrm{GaN}$-based HEMT structure as well. Experimental investigations are being carried out and will report in future.

\section{Conclusions}

In this work, we have demonstrated the material growth and the detailed structural characterization of a $\mathrm{B}_{0.14} \mathrm{Al}_{0.86} \mathrm{~N} / \mathrm{GaN}$ heterojunction and proved that their interface was abrupt with epitaxial relationship. The VBO between $\mathrm{B}_{0.14} \mathrm{Al}_{0.86} \mathrm{~N} /$ and $\mathrm{GaN}$ is determined to be $-0.2 \pm 0.2 \mathrm{eV}$, confirming a type-I band alignment. Furthermore, the $\mathrm{CBO}$ value is also estimated to be $2.1 \pm 0.2 \mathrm{eV}$. Such high $\mathrm{CBO}$ and low VBO are the critical parameters to design group-III nitrides based light emitters and power transistors. We provide two examples in exploring such applications. For instance, the band offsets are promising to offer significant electron confinement without hindering the hole injection in a light emitting device. Moreover, they can be utilized in power device due to the enhancement of the 2DEG in such junctions, showing its potentials for the power electronics application.

Finally, we acknowledge the funding support from KAUST Baseline BAS/1/1664-01-01, KAUST Competitive Research Grant URF/1/ 3437-01-01, and the GCC Research Program REP/1/3189-01-01. Y.J.P, T.D, and R.D.D. at Georgia Tech acknowledge the funding support from NSF under Grant No. DMR-1410874 and the DARPA under Grant No. W911NF-15-1-0026, and also the support of the Georgia Research Alliance and the Steve W. Chaddick Endowed Chair in Electro-Optics.

\section{References}

[1] H. Amano, Y. Baines, E. Beam, M. Borga, T. Bouchet, P.R. Chalker, M. Charles, K.J. Chen, N. Chowdhury, R. Chu, et al., J. Phys. D: Appl. Phys. 51 (2018), 163001.

[2] J. Hu, S. Stoffels, S. Lenci, B. Bakeroot, B. De Jaeger, M. Van Hove, N. Ronchi, R. Venegas, H. Liang, M. Zhao, IEEE T. Electron Dev. 63 (2016) 997.

[3] L.-Y. Su, F. Lee, J. Huang, IEEE T. Electron Dev. 61 (2014) 460.

[4] Y. Zhang, D. Piedra, M. Sun, J. Hennig, A. Dadgar, L. Yu, T. Palacios, IEEE Elec tron. Dev.Lett. 38 (2017) 248.

[5] D. Ji, S. Chowdhury, IEEE T. Electron Dev. 62 (2015) 2571.

[6] A. Lidow, J. Strydom, M. De Rooij, D. Reusch, GaN Transistors for Efficient Power Conversion, Chapter. 1 Wiley, West Sussex, 2015.

[7] U. Mishra, P. Parikh, Y.-F. Wu, Proc. IEEE 90 (2012) 1022.

[8] M. Zhang, X. Li, Phys. Status Solidi B 254 (2017) 1600749.

[9] K. Liu, H. Sun, F. AlQatari, W. Guo, X. Liu, J. Li, C.G.T. Castanedo, X. Li, Appl. Phys. Lett. 111 (2017), 222106.

[10] S.H. Park, D. Ahn, Appl. Phys. Exp. 9 (2016) 02100.

[11] M. Abid, T. Moudakir, G. Orsal, S. Gautier, A. En, Z. Naciri, J.H. Djebbour, G. Ryou, L. Patriarche, H.J. Largeau, Z. Kim, K. Lochner, D. Pantzas, F. Alamarguy, R.D. Jomard, J.P. Dupuis, P.L. Salvestrini, Voss, and A. Ougazzaden, Appl. Phys. Lett. 100 (2012), 051101.

[12] X. Li, S. Wang, H. Liu, F. Ponce, T. Detchprohm, R.D. Dupuis, Phys. Status Solidi B 254 (2017) 1600699.

[13] S. Wang, X. Li, A.M. Fischer, T. Detchprohm, R.D. Dupuis, F.A. Ponce, J. Cryst. Growth 475 (2017) 334

[14] H. Sun, F. Wu, Y.J. Park, C.H. Liao, W. Guo, N. Alfaraj, K.H. Li, D.H. Anjum, T. Detchprohm, R.D. Dupuis, X. Li, Appl. Phys. Exp. 11 (2017), 011001.

[15] H. Sun, Y. Park, K.-H. Li, C.G.T. Castanedo, A.S. Alowayed, T. Detchprohm, R.D. Dupuis, X. Li, Appl. Phys. Lett. 111 (2017), 122106.

[16] H. Sun, C.G.T. Castanedo, K. Liu, K.-H. Li, W. Guo, R. Lin, X. Liu, J. Li, X. Li, Appl. Phys. Lett. 111 (2017), 162105.

[17] Q. Wang, X. Cheng, L. Zheng, L. Shen, D. Zhang, Z. Gu, R. Qian, D. Cao, Y. Yu, Appl. Surf. Sci. 428 (2018) 1-6.

[18] Z.Q. Feng, Q. Feng, J.C. Zhang, X. Li, F.G. Li, L. Huang, H.Y. Chen, H.L. Lu, Y. Hao, Appl. Surf. Sci. 434 (2017) 440.

[19] E.A. Kraut, R.W. Grant, J.R. Waldrop, S.P. Kowalczyk, Phys. Rev. Lett. 44 (1980) 1620.

[20] W.E. Moddeman, A.R. Burke, W.C. Bowling, D.S. Foose, Surf. Interf. Anal. 14 (1989) 224.

[21] O. Ambacher, J. Smart, J.R. Shealy, N.G. Weimann, K. Chu, M. Murphy, W.J. Schaff, L.F. Eastman, R. Dimitrov, L. Wittmer, M. Stutzmann, W. Rieger, J. Hilsenbeck, J. Appl. Phys. 85 (1999) 3222.

[22] S. Pearton, GaN and ZnO-based Materials and Devices, Chapter 2 Springer, New York, 2012.

[23] G. Martin, A. Botchkarev, A. Rockett, H. Morkoç, Appl. Phys. Lett. 68 (1996) 2541.

[24] O. Ambacher, B. Foutz, J. Smart, J.R. Shealy, N.G. Weimann, K. Chu, M. Murphy, A.J. Sierakowski, W.J. Schaff, L.F. Eastman, R. Dimitrov, A. Mitchell, M. Stutzmann, J. Appl. Phys. 87 (2000) 334.

[25] < http://crosslight.com/products/apsys/>

[26] P. Smorchkova, L. Chen, T. Mates, L. Shen, S. Heikman, B. Moran, S. Keller, S.P. DenBaars, J.S. Speck, U.K. Mishra, J. Appl. Phys. 90 (2001) 5196.

[27] E. Bellotti, F. Bertazzi, M. Goano, J. Appl. Phys. 101 (2007), 123706.

[28] M. Miyoshi, H. Ishikawa, T. Egawa, K. Asai, M. Mouri, T. Shibata, M. Tanaka, O. Oda, Appl. Phys, Lett. $85(2004) 1710$. 